American Journal of Applied Sciences 9 (9): 1491-1495, 2012

ISSN 1546-9239

(C) 2012 Science Publication

\title{
Voltage Stability of Long Transmission Line Equipped with a Thyristor Controlled Series Capacitor
}

\author{
Prechanon Kumkratug \\ Division of Electrical Engineering, Faculty of Engineering at Si Racha, \\ Kasetsart University, 199 M.6, Tungsukhla, Si Racha, Chonburi, 20230, Thailand
}

\begin{abstract}
Problem statement: Power-Voltage curve provides very important information for voltage stability analysis. The exact long transmission line model consists of the resistance and the reactance. The resistance causes in the active line loss. It is not easy task to achieve the power-voltage curve characteristics of power system with the exact long line model equipeed with a Thyristor Controlled Series Capacitor (TCSC). Approach: This study applies the concept of the Newton-Raphson method to iteratively solve the nonlinear power flow equations. The Power-Voltage $(\mathrm{P}-\mathrm{V})$ curve charateristic of the system without line loss and with line loss are plotted and compared on various cases. Results: It is found from the study that the resistance of the line obviously provides the negative effects on the voltage stability. The line loss causes in the decrement of the critical point. In addition, it is found that the leading power factor can increase the critical point of P-V curve. Conclusion: The exact long line model should be considered for voltage stability analysis of the system with the long transmission line.
\end{abstract}

Key words: Thyristor Controlled Series Capacitor (TCSC), Power-Voltage (P-V), Critical Clearing Time (CCT), Flexible AC Transmission System (FACTS)

\section{INTRODUCTION}

Power system stability is classified as rotor angle stability and voltage stability. Voltage stability is a stability in power systems which are heavily loaded, distubeanced or have a shortage of reactive power. Nowadays, the demand of electricity has dramatically increased and a modern power system becomes a complex network of transmission lines interconnecting the generating stations to the major loads points in the overall power system in order to support the high demand of consumers. It is becoming increasingly important to fully utilize the existing transmission system assets due to environmental legislation, rightsof-way issues and costs of construction and deregulation policies that introduced in recent years. A number of Flexible AC Transmission System (FACTS) controllers, based on the rapid development of power electronics technology, have been proposed for better utilization of the existing transmission systems (Gonzalez et al., 2010; Sonmez et al., 2012; Thirumalaivasan et al., 2012; Wibowo et al., 2011).

The evaluation of the Power-Votage (P-V) curve of the power system is one of the most important research areas for power engineers because it indicates the maximum power load. If the load is increased beyond the maximu value, the voltage will be collapsed and then the system is considered as unstable.
The Thyristor Controlled Series Capacitor (TCSC) is the series FACTS devices. It consists of the capacitor bank reactor bank and thyristor as shown in Fig. 1. The thyristors control the reactance or susceptance that dictates the power flow through a line. The TCSC can be applied for improving stability of power system (Chakrabortty, 2012).

The evaluation of Critical Clearing Time (CCT) of power system is one of the most important research areas for power engineers because it indicates the robustness of the faulted power system. The rotor angle of the synchronous generator determines the stability of power system. Although the stability of the synchronous machine is used to represent the stability of the power system, all of the power system components such as transmission line and transformer affect the stability of the power system.

The transmission line is one of the most important parts in power system components. Most of the fault occurs at the transmission line. The transmission line is generally divided into three major categories; short, medium and long model whose distance are about 80 $\mathrm{km}$, above $80-250 \mathrm{~km}$ and above $250 \mathrm{~km}$, respectively. Many previous researches used simple transmission line model by neglecting its resistance or capacitance. To fully utilization the existing system, the exact transmission line should be further investigated. 


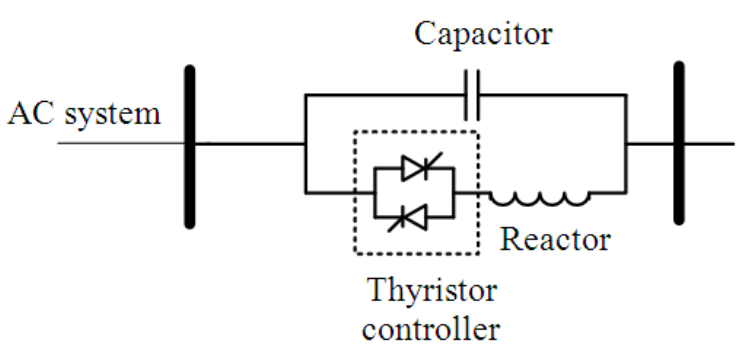

Fig. 1: Schematic diagram of TCSC

This study will investigate the capability of the TCSC on voltage stability of the SMIB system with the exact long transmission line model. The concept of two-port network is applied to simplify the mathematical model of the power system. The sample system consisting the practical long transmission line is used to investigate in this study. The proposed method is tested on various cases.

\section{MATERIALS AND METHODS}

Mathematical model: Consider the simple system with the lump of nominal $\pi$ model as shown in Fig. 2a. The generator supplies the active power and reactive power, which is transferred through a transmission line to the load. The voltage, active power and reactive power at load are represented by $V_{R}, P_{R}$ and $Q_{R}$, respectively. The voltage at generator bus $\left(\mathrm{V}_{\mathrm{S}}\right)$ is considered as constant value. The lump of the nominal $\pi$ model is represented by a equivalent $\pi$ model as shown in Fig. $2 \mathrm{~b}$ in two ports network are given Eq. 1-4:

$A=\left(1+Y^{\prime} Z^{\prime} / 2\right)$

$\mathrm{B}=\mathrm{Z}^{\prime}$

$\mathrm{C}=\mathrm{Y}^{\prime}\left(1+\mathrm{Y}^{\prime} \mathrm{Z}^{\prime} / 4\right)$

$\mathrm{D}=\mathrm{A}$

The equivalent $Z^{\prime}$ is given by:

$\mathrm{Z}^{\prime}=\mathrm{Z}_{\mathrm{c}} \sinh \gamma \mathrm{l}$

The equivalent $Y^{\prime}$ is given by:

$\mathrm{Y}^{\prime}=\frac{2}{\mathrm{Z}_{\mathrm{c}}} \sinh \frac{\gamma \mathrm{l}}{2}$

Here the $\gamma$ and $Z_{c}$ in Eq. 5 and 6 are given by:

$\gamma=\sqrt{\mathrm{ZY}} / 1$
And:

$Z_{c}=\sqrt{\frac{Z}{Y}}$

The ABCD constants of a TCSC in two ports network are given by Eq. 9-12:

$\mathrm{A}_{\mathrm{TCSC}}=1$

$\mathrm{B}_{\mathrm{TCSC}}=-\mathrm{j} \mathrm{X}_{\mathrm{TCSC}}$

$\mathrm{C}_{\mathrm{TCSC}}=0$

$\mathrm{D}_{\mathrm{TCSC}}=1$

With the series combination of a transmission line and TCSC in two ports network as shown in Fig. 2b, a successive two ports networks is shown in Fig. 2c and d its constant parameters are given by Eq. 13-16:

$\mathrm{A}_{\text {eq }}=\mathrm{A}_{1} \mathrm{~A}_{\mathrm{TCSC}}+\mathrm{B}_{1} \mathrm{C}_{\mathrm{TCSC}}$

$\mathrm{B}_{\text {eq }}=\mathrm{A}_{1} \mathrm{~B}_{\mathrm{TCSC}}+\mathrm{B}_{1} \mathrm{D}_{\mathrm{TCSC}}$

$\mathrm{C}_{\mathrm{eq}}=\mathrm{A}_{\mathrm{TCSC}} \mathrm{C}_{1}+\mathrm{C}_{\mathrm{TCSC}} \mathrm{D}_{1}$

$\mathrm{D}_{\mathrm{eq}}=\mathrm{B}_{\mathrm{TCSC}} \mathrm{C}_{1}+\mathrm{D}_{1} \mathrm{D}_{\mathrm{TCSC}}$

Then the active and reactive power load are given by Eq. 17 and 18:

$\mathrm{P}_{\mathrm{R}}=\frac{\mathrm{V}_{\mathrm{R}} \mathrm{V}_{\mathrm{S}}}{\mathrm{B}_{\mathrm{eq}}} \cos \left(\theta_{\mathrm{B}}-\delta\right)-\frac{\mathrm{A}_{\mathrm{eq}} \mathrm{V}_{\mathrm{R}}^{2}}{\mathrm{~B}_{\mathrm{eq}}} \cos \left(\theta_{\mathrm{B}}-\theta_{\mathrm{A}}\right)$

And:

$\mathrm{Q}_{\mathrm{R}}=\frac{\mathrm{V}_{\mathrm{R}} \mathrm{V}_{\mathrm{S}}}{\mathrm{B}_{\mathrm{eq}}} \sin \left(\theta_{\mathrm{B}}-\delta\right)-\frac{\mathrm{A}_{\mathrm{eq}} \mathrm{V}_{\mathrm{R}}^{2}}{\mathrm{~B}_{\mathrm{eq}}} \cos \left(\theta_{\mathrm{B}}-\theta_{\mathrm{A}}\right)$

The objective of this study is to evaluate the voltage at load bus $\left(\mathrm{V}_{\mathrm{R}}\right)$ with various cases of load. This study applies the Newton-Raphson method to iteratively solve the nonlinear Eq. 13 and 14 given by

$\left[\begin{array}{c}\Delta \mathrm{P}_{\mathrm{R}} \\ \Delta \mathrm{Q}_{\mathrm{R}}\end{array}\right]=\left[\begin{array}{cc}\frac{\partial \mathrm{P}_{\mathrm{R}}}{\partial \delta} & \frac{\partial \mathrm{P}_{\mathrm{R}}}{\partial \mathrm{V}_{\mathrm{R}}} \\ \frac{\partial \mathrm{Q}_{\mathrm{R}}}{\partial \delta} & \frac{\partial \mathrm{Q}_{\mathrm{R}}}{\partial \mathrm{V}_{\mathrm{R}}}\end{array}\right]\left[\begin{array}{c}\Delta \delta \\ \Delta \mathrm{V}\end{array}\right]$ 


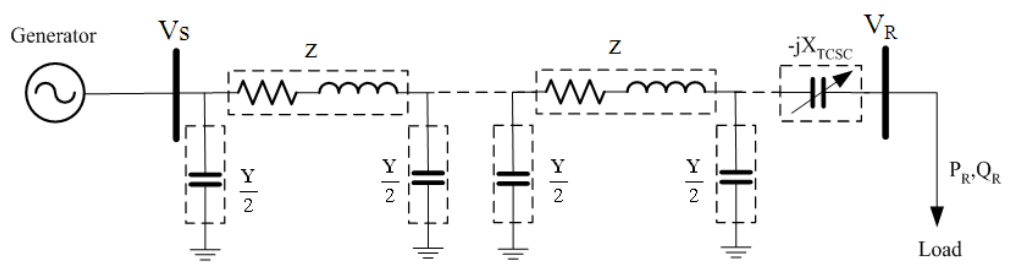

(a)

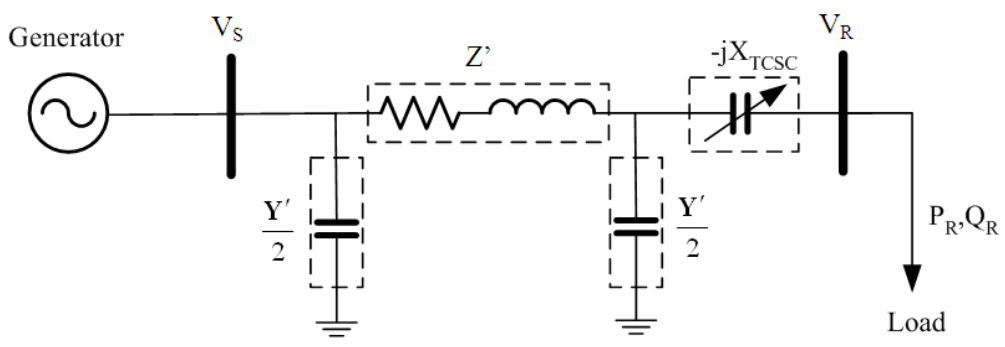

(b)

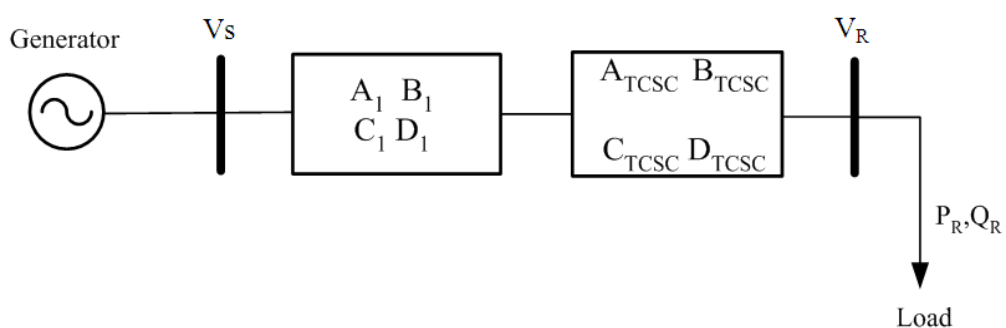

(c)

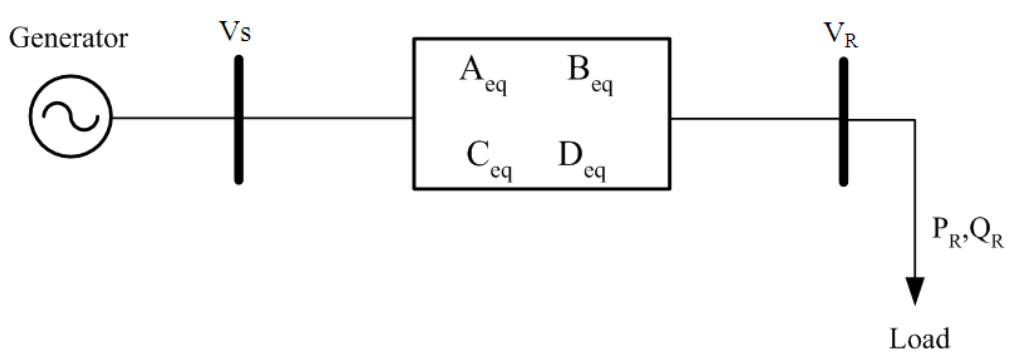

(d)

Fig. 2: Single machine infinite bus system with a TCSC (a) schematic diagram (b) equivalent circuit (c) two ports network diagram (d) a successive two-ports network

\section{RESULTS}

The proposed method is tested on the sample system consider the diagram of sample system is shown in Fig. 2. The system supplies power which is transferred through a $40 \mathrm{~km}$ transmission line to the load. The system voltage at the generator bus is $340 \mathrm{kV}$. It is considered that the variable capacitive reactance of a TCSC is operated at $20 \%$ of the line reactance. The comparison of the Power-Voltage (P-V) curve of the system with and without a TCSC for various power factors is shown in Fig. 3-7. Table 1 summarizes the critical point $\left(\mathrm{P}_{\mathrm{R}}^{\mathrm{cr}}, \mathrm{V}_{\mathrm{R}}^{\mathrm{cr}}\right)$ of the system without and with a TCSC for various power factors.

Table 1: The maximum and minimum rotor angle of the system with a TCSC and various parameters of the long transmission line

\begin{tabular}{lcrccc}
\hline & & \multicolumn{2}{l}{ Without TCSC } & \multicolumn{2}{l}{ With a TCSC } \\
Case & Tan $\phi$ & $\mathrm{P}_{\mathrm{R}}^{\text {cr }}(\mathrm{W})$ & $\mathrm{V}_{\mathrm{R}}^{\text {cr }}(\mathrm{kV})$ & $\mathrm{P}_{\mathrm{R}}^{\text {cr }}(\mathrm{W})$ & $\mathrm{V}_{\mathrm{R}}^{\text {cr }}(\mathrm{kV})$ \\
\hline 1 & 0.4 & 835 & 307 & 1073 & 309 \\
2 & 0.2 & 996 & 325 & 1273 & 326 \\
3 & 0.0 & 1191 & 352 & 1514 & 349 \\
4 & -0.2 & 1418 & 388 & 1790 & 385 \\
5 & -0.4 & 1670 & 433 & 2090 & 426 \\
\hline
\end{tabular}




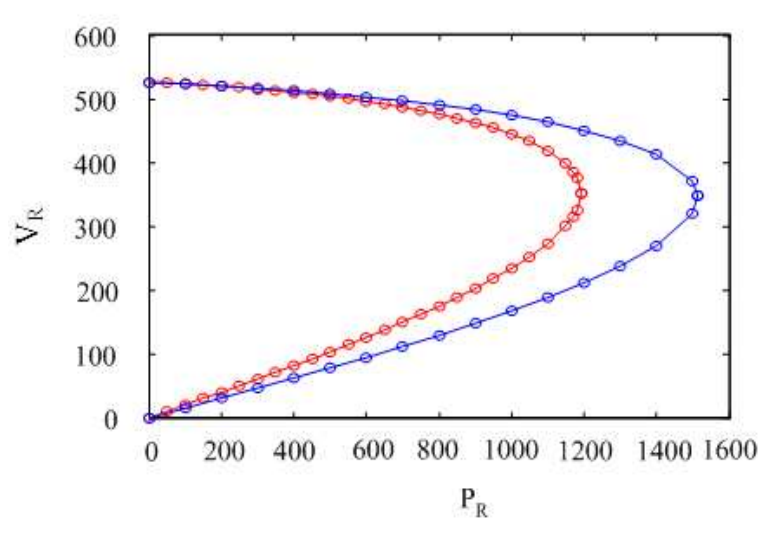

Fig. 3: P-V curve of the system without and with a TCSC for unity power facto

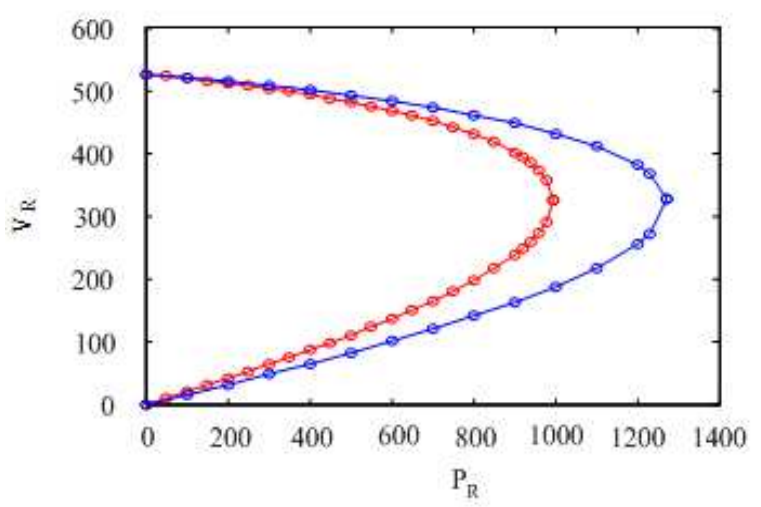

Fig. 4: P-V curve of the system without and with a TCSC for $\tan \phi-0.0 .2$

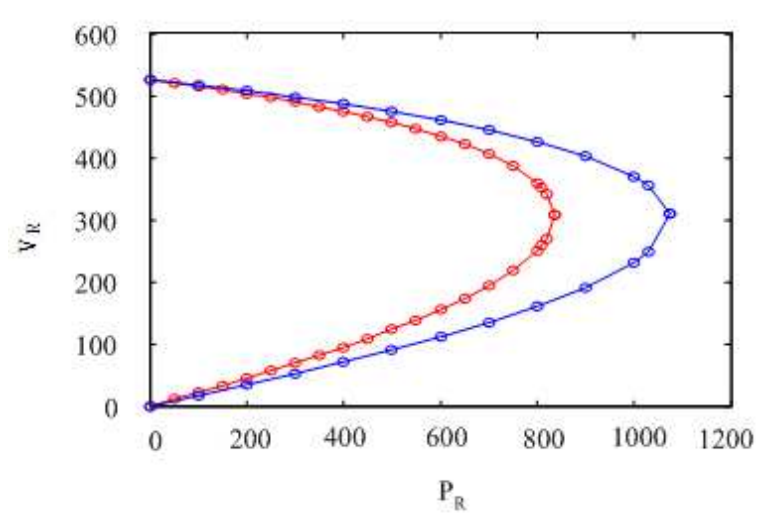

Fig. 5: P-V curve of the system without and with a TCSC for $\tan \phi-0.0 .4$

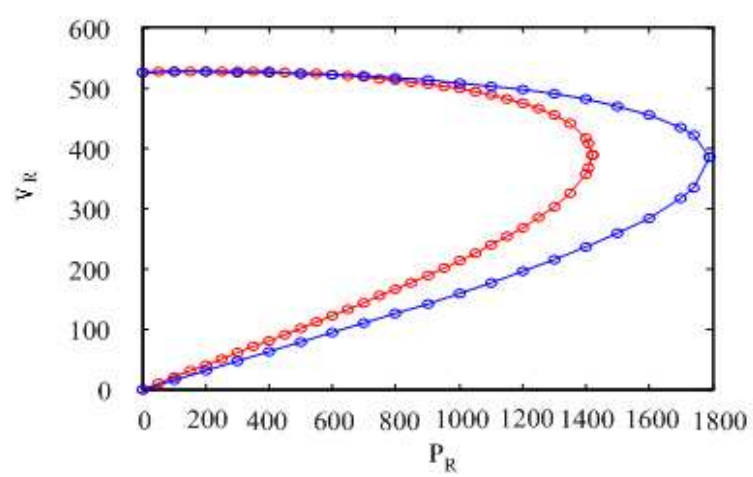

Fig. 6: P-V curve of the system without and with a TCSC for $\tan \phi-0.0 .2$

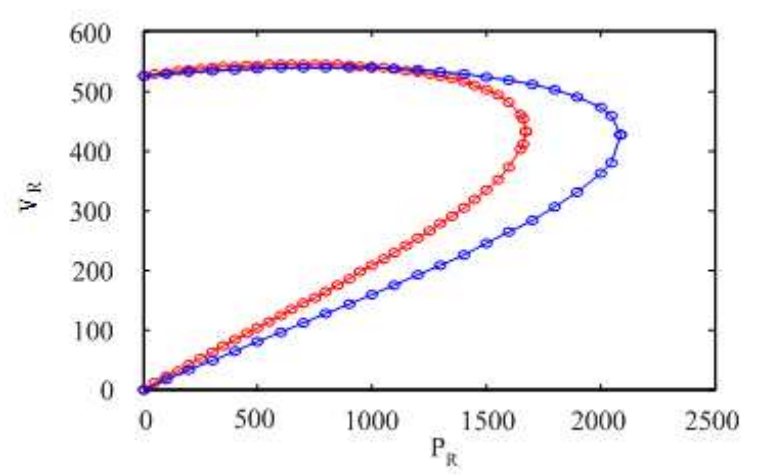

Fig. 7: P-V curve of the system without and with a TCSC for $\tan \phi-0.0 .4$

\section{DISCUSSION}

It can be seen from the Fig. 3-7 and the Table that a TCSC can improve voltage stability of the system. Without a TCSC and unity power, the critical point $\left(\mathrm{P}_{\mathrm{R}}^{\mathrm{cr}}, \mathrm{V}_{\mathrm{R}}^{\mathrm{cr}}\right.$ ) is at $1191 \mathrm{~W}$ and $352 \mathrm{kV}$. In this case, it indicates that the maximumum power load is around $1191 \mathrm{~W}$. However, with a TCSC, the maxmum power load is increased to $1514 \mathrm{~W}$. This study investigates the effect of power factor on the critical point. With the lagging power factor, the crtical point point is reduced whereas with the leading power factor, the crtical point point is increased. With $\tan \phi=0.4$ and with a TCSC, the maximum power is reduced to $1073 \mathrm{~W}$ whereas tan $\phi=-0.4$ and with a TCSC, the maximum power is increased to $2090 \mathrm{~W}$.

\section{CONCLUSION}

This study investigated the effects of the Thyristor Controlled Series Capacitor (TCSC) on the voltage 
stability improvement of the Single Machine Infinite Bus (SMIB) system with the consideration of the exact long transmission line model. The mathematical model was systematically derived by using the concept of the two-port network. This concept can help us to obtain mathematical model of the system in the simpler way.

The presented methods were tested and compared on various cases. It was found from the simulation results that the TCSC improve the voltage stability performance. The leading power factor and a TCSC operated in capacitive mode can improve voltage stability.

\section{REFERENCES}

Chakrabortty, A., 2012. Wide-area damping control of power systems using dynamic clustering and TCSC-based redesigns. IEEE Trans. Smart Grid. DOI: 10.1109/TSG.2012.2197029

Gonzalez, M.J., C.A. Canizares and J.M. Ramirez, 2010. Stability modeling and comparative study of series vectorial compensators. IEEE Trans. Power Syst., 25: 1093-1103. DOI: 10.1109/TPWRD.2009.2034905
Sonmez, Y., U. Guvenc, S. Duman and N. Yorukeren, 2012. Z-sourced unified power flow controller. Proceedings of the 6th IET International Conference on Power Electronics, Machines and Drives, Mar. 27-29, Bristol, UK., 1-7. DOI: 10.1049/cp.2012.0222

Thirumalaivasan, R., M. Janaki and N. Prabhu, 2012. Damping of SSR using subsynchronous current suppressor with SSSC. IEEE Trans. Power. Syst. DOI: 10.1109/TPWRS.2012.2193905

Wibowo, R.S. N. Yorino, M. Eghbal, Y. Zoka and Y. Sasaki, 2011. FACTS devices allocation with control coordination considering congestion relief and voltage stability. IEEE Trans. Power Syst., 26: 2302-2310. DOI: 10.1109/TPWRS.2011.2106806 